\title{
THE MITRAL VALVE IN ENDOCARDIAL CUSHION DEFECTS
}

\author{
BY \\ M. AL OMERI, MONICA BISHOP, CELIA OAKLEY*, H. H. BENTALL, \\ AND W. P. CLELAND
}

From the Departments of Medicine (Clinical Cardiology) and Surgery, Hammersmith Hospital and Postgraduate Medical School of London

Received June 5, 1964

Since 1957, 29 cases of endocardial cushion defect have been operated upon in this hospital. They included an appreciable number of the more complex forms of the anomaly, and in these, as has been the experience of other workers (Cooley, Latson, and Keats, 1958; Kiely et al., 1958; Gerbode et al., 1961, and Scott, Hauck, and Nadas, 1962a), the over-all mortality was distressingly high. There were, however, a number of deaths among the apparently simple cases. Reviewing the causes of death in these "simple" cases suggested that persistence of mitral incompetence had played a dominant role. Difficulty was experienced in repairing the mitral valve because the anatomy was more complicated than had been expected, and of a kind not previously stressed.

The problems presented by these patients prompted us to review the group as a whole for there appeared to be a lack of correlation between the clinical evaluation and the findings at operation. We considered it desirable to clarify the anatomy of the lesion and the adequacy of methods for its assessment and treatment, paying particular attention to the mitral valve and the ways in which its form and function might best be determined.

\section{Terminology and Classification}

The term "endocardial cushion defect" covers a wide range of embryologically related congenital cardiac anomalies from the so-called simple ostium primum at one end of the scale to the complete atrio-ventricular canal at the other. There appears to be little virtue in considering either of these two extremes as separate entities since this leaves a large group of intermediate forms unclassified, and implies that there is a clear-cut distinction between groups, which is fallacious. While no classification is entirely satisfactory, for practical purposes we use that of Campbell and Missen (1957) who grouped them in three grades of increasing complexity.

The embryological development of the endocardial cushions and the part that they play in the final formation of the central portions of the heart have been clearly outlined by van Mierop and his colleagues (1962). Briefly, the endocardial cushions are a dorsal (posterior) and ventral (anterior) mass of mesenchyme which grow, fuse, and become so modelled that they divide the atrio-ventricular canal into two orifices - the mitral and tricuspid valves. At the same time, however, they contribute to the atrio-ventricular septum and membranous septum as well as to the valve cusps and their chordæ. Each endocardial cushion provides two half leaflets, and on the right side there is an additional contribution from the conus septum. The distribution of these elements in the mature heart is shown superimposed on photographs of the right and left sides of a normal child's heart in Fig. 1.

* In receipt of a grant from the British Heart Foundation. 
(a)

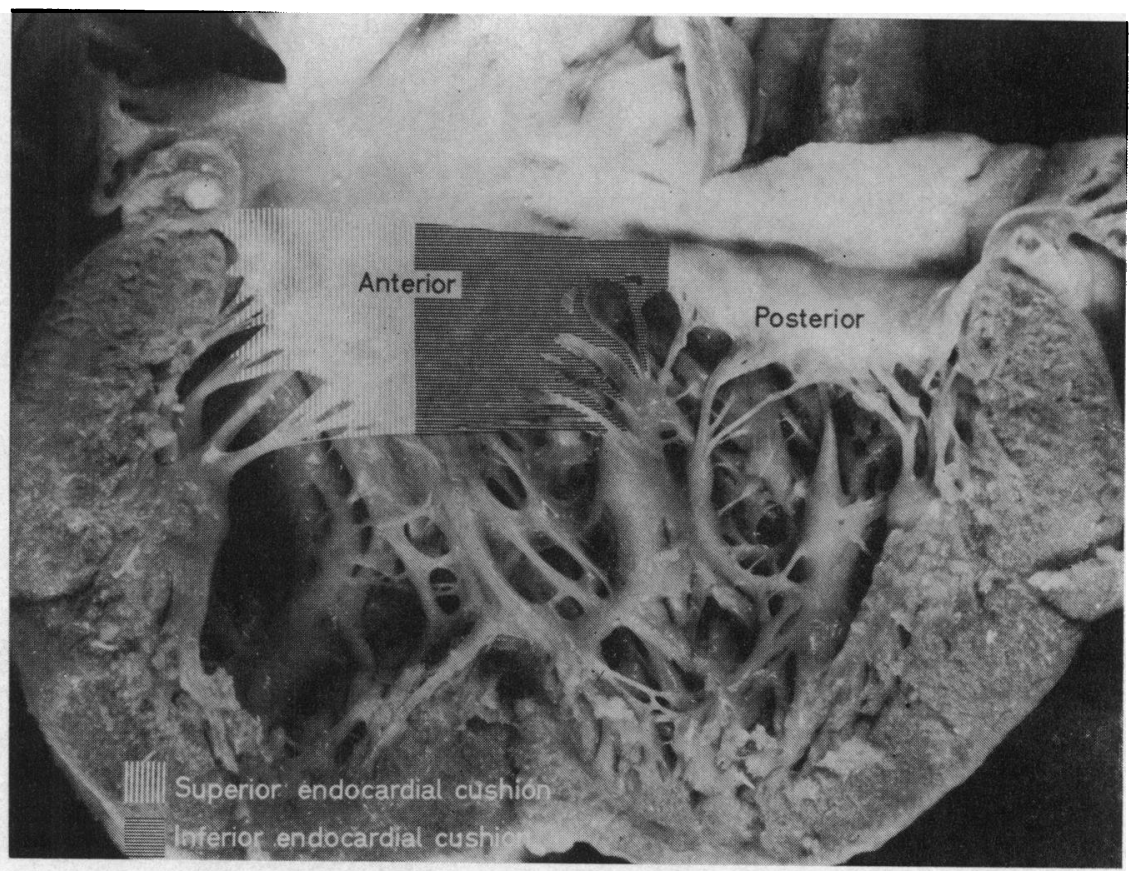

(b)

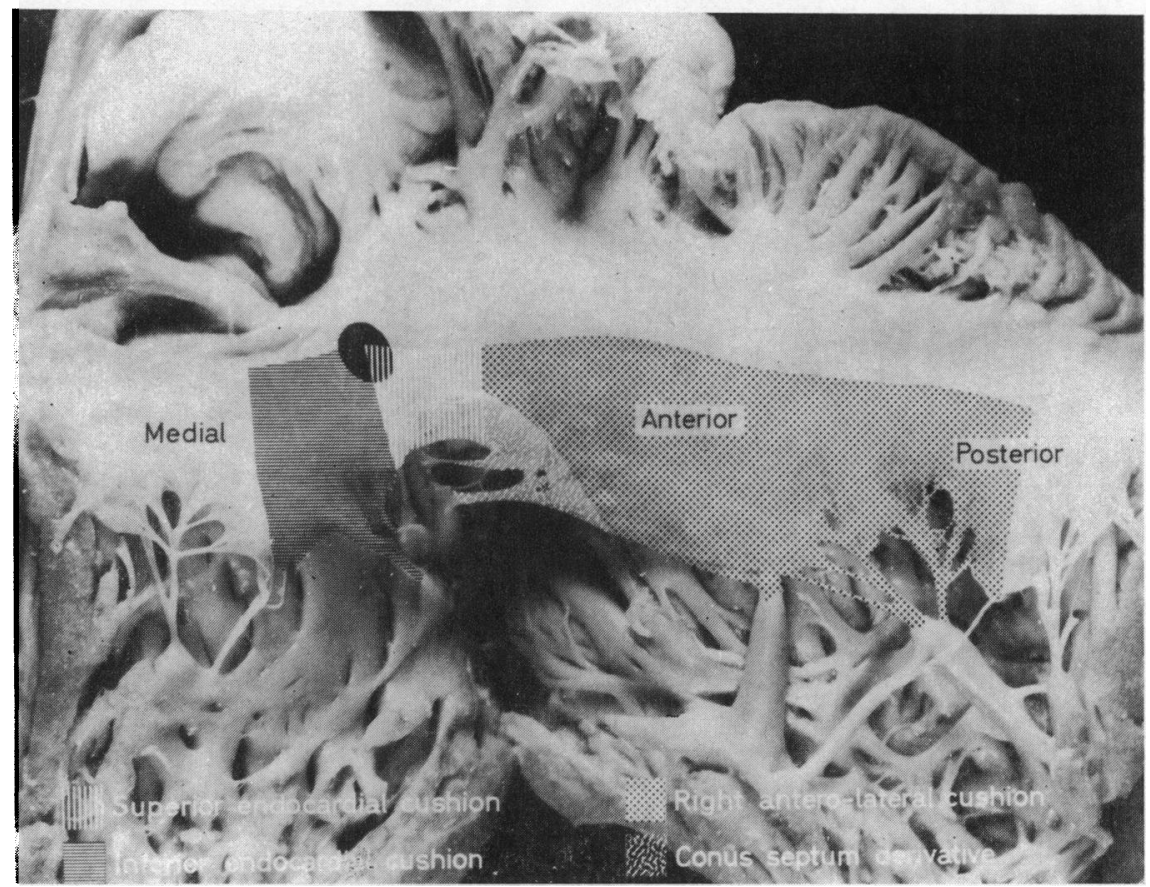

Fig. 1.-Photographs of the right and left sides of a normal child's heart to show the components of the mitral (a) and tricuspid (b) valves and the distribution of the endocardial cushion tissue in them. (The solid dark area in (b) is the membranous septum.) 


\section{Anatomy of Endocardial Cushion Defects}

For proper perspective it is essential to appreciate the normal sites of fusion of the formative elements in all planes. In Fig. 2 the essential features of the various grades of endocardial cushion defect are depicted in diagrammatic section in the frontal plane.

Grade I: Ostium primum with cleft mitral valve. There is a defect in the basal portion of the atrial septum with a crescentic upper margin. The atrioventricular valve rings are formed and have fused with the upper edge of the ventricular septum which is defective in the sense that the upper edge, being incomplete, has a scooped-out appearance. The anterior leaflet of the mitral valve is cleft in nearly all cases, and the valve is attached to the ventricular septum at the same level as the tricuspid valve, and not in its usual more elevated position (Fig. 2, grade I).

The crescentic upper margin of the primum defect in the atrial septum represents the line along which the anterior mitral cusp is attached in the normal heart. It is extremely rare for the primum defect to exist without some degree of deformity of the mitral valve. It was encountered only once by Abbott in over 1000 necropsies on cases of congenital heart disease.

Grade II: The transitional forms. Many variations are possible, but they fall into three main types.

(a) The commonest of them has the primum defect and partial fusion of the atrio-ventricular valve rings which are attached to the ventricular septum by short thick chordæ (Fig. 2, grade IIa).

$(b)^{*}$ There may be no interatrial communication, but a cleft mitral valve is abnormally attached to the deficient ventricular septum, the so-called cushion type of ventricular septal defect. In these cases the tricuspid valve ring forms one margin of the defect and the tricuspid valve may be abnormal. Unlike the usual infracristal defects a ridge of tissue separates the upper rim of the defect from the aortic valve ring (Fig. 2, grade IIb).

(c)* The rarest transitional form is that in which the mitral valve is normally formed, but there is a cleft or defective formation of the tricuspid septal cusp and a communication in the region of the membranous septum between the left ventricle and the right atrium (Fig. 2, grade IIc).

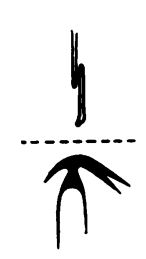

Grade I.
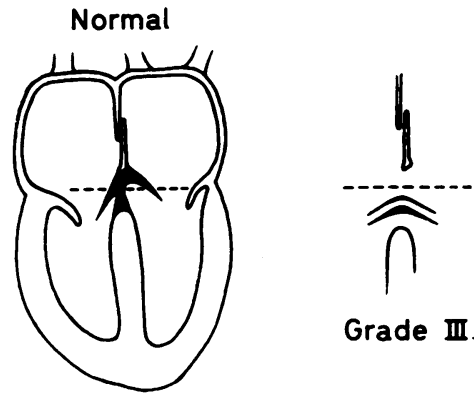

Grade III
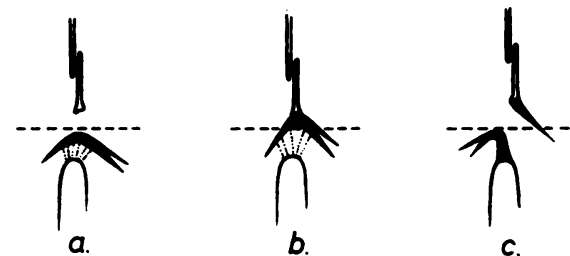

Grade II.

FIG. 2.-Diagrammatic sections in the frontal plane to show the normal sites of fusion of the endocardial cushion tissue compared with the situation in the three grades of this type of defect. The endocardial cushion tissue is drawn in solid black. In the centre is the normally formed heart showing fusion of the endocardial cushions with the atrial and ventricular septa above and below. The horizontal dotted line (drawn at the same level in each diagram) shows the normal level of attachment of the atrio-ventricular (A-V) valves. Note that the mitral valve (on the right of the diagram) is normally higher than the tricuspid valve. The region of the atrio-ventricular canal alone is shown enlarged in the other diagrams. The ostium primum defect with its cleft and inferiorly displaced mitral valve is shown in the upper left-hand corner. The transitional defects are depicted below. Grade IIa shows an ostium primum defect where there is also abnormal attachment of the chordæ to the top of the ventricular septum (the tricuspid valve may also be cleft or otherwise deficient). Grade IIb is entirely an interventricular communication, the isolated ventricular septal defect of A-V canal type or "cushion VSD". Abnormal chordæ are shown, and the mitral valve may be cleft (the tricuspid valve may or may not be similarly abnormal). Grade IIc shows the situation in which the defect is in that part of the membranous septum that separates the left ventricle from the right atrium. The mitral valve is normal but the tricuspid valve is abnormal and often cleft. In the upper righthand corner is shown the complete $\mathrm{A}-\mathrm{V}$ canal in which all four cardiac chambers are in communication with each other and the single A-V valve straddles the defect but is not tethered to the top of the ventricular septum.

\footnotetext{
* Patients with isolated ventricular septal defects of the endocardial cushion type but without mitral incompetence or proven mitral valve clefts have been excluded and so have patients with left ventricular-right atrial shunts for they do not come within the scope of this article.
} 


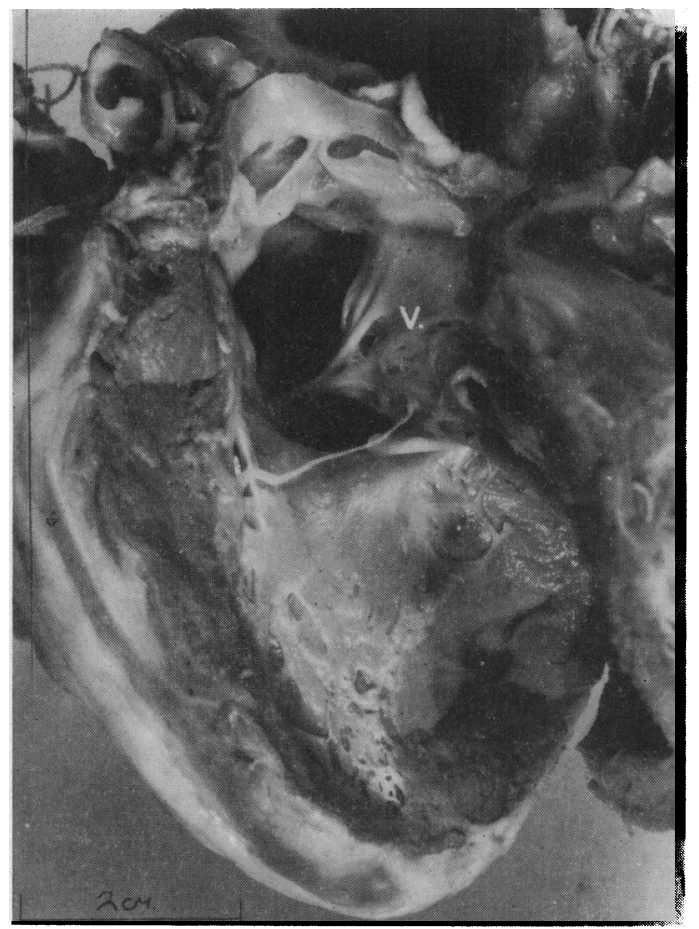

Fig. 3.- Heart opened to show the left ventricle and aortic outflow tract (patient J.F.). There is a single atrio-ventricular valve (V) held only by the chordal attachments to the papillary muscles on either side of the septum (grade III defect).

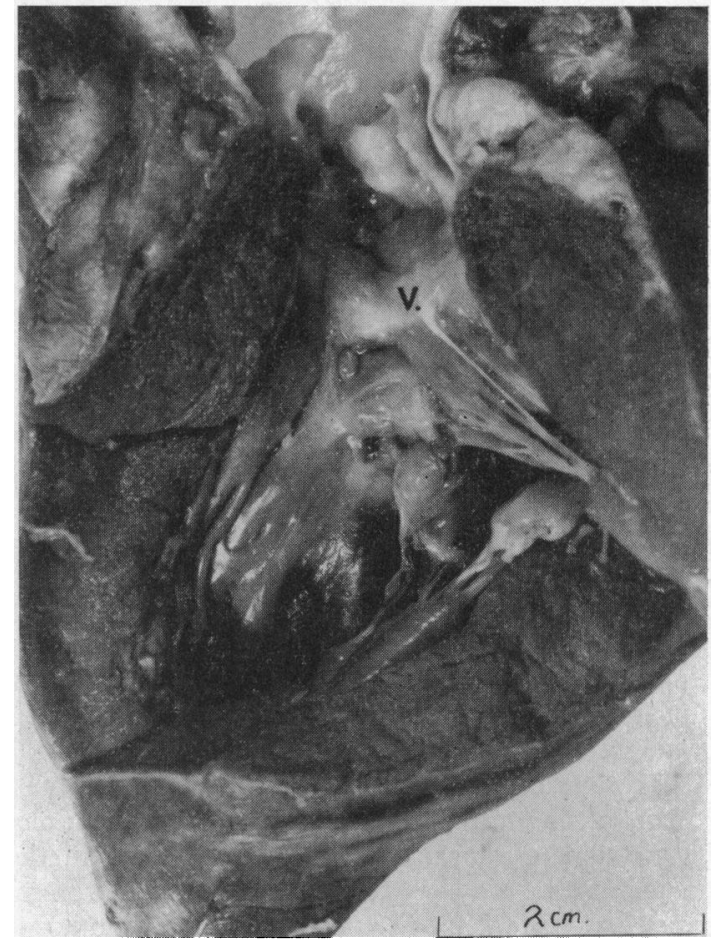

FIG. 4.-The view is the same as in Fig. 3, but here the anterior part of the atrio-ventricular valve (V) is attached to the edge of the deeply shelved ventricular septum, and the aortic outflow tract is elongated and narrowed (patient S.T.) (grade I defect).

Grade III: Complete atrio-ventricular canal. In this complete form there is a large communication between the atria and ventricles which is straddled by the unfused leaflets of the common valve. The cusps are often ill defined, and the anterior and posterior portions of such a common valve, though lying quite close together, may be completely unattached to the upper edge of the ventricular septum, and held in place only by their chordæ passing to the appropriate papillary muscles. There may be additional short chordæ passing to the upper edge of the septum, and occasionally the anterior portion of this common cusp may be adherent to the anterior margin of the shelving septum, in which case the aortic outflow is very narrowed and elongated (Fig. 2, grade III).

Certain features deserve special emphasis in all three types (Fig. 3 to 6). First, the deformed mitral valve may be functionally normal despite the cleft and abnormal chordal attachments, but in the majority of cases the complex abnormality of this valve gives rise to some degree of incompetence that varies from the mild to the very severe. The edges of the mitral cleft are often rolled and thickened, and additional short chordæ attached abnormally to the top of the ventricular septum, tethering and immobilizing the edges of the cleft, are quite common (Edwards, 1960). There is, in addition, a further element to the deformity of the valve in some cases of the partial and transitional forms of the anomaly which is probably an effect of the downward displacement of the valve in that the attachment of the valve cusps to the papillary muscles may well also be abnormal. We have several times encountered the situation where a papillary muscle (usually the posterior one) is attached into the valve ring, and the chordæ from the valve cusps attach into the side instead of into the apex of the papillary muscle. Such an arrangement severely limits the mobility of the valve cusps. Severance of these chordæ (as opposed to those running to the top of 


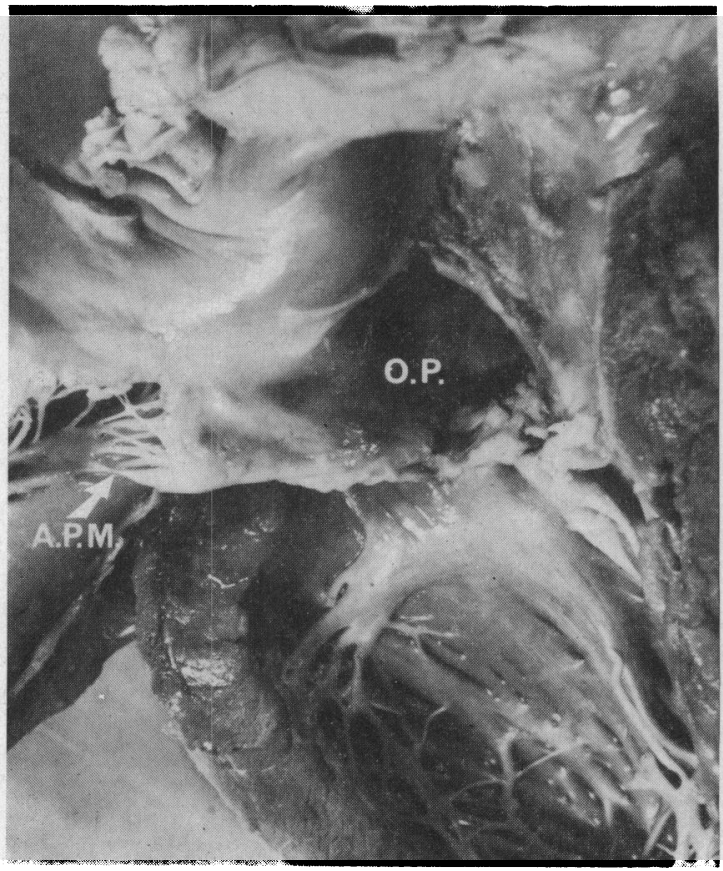

(a)

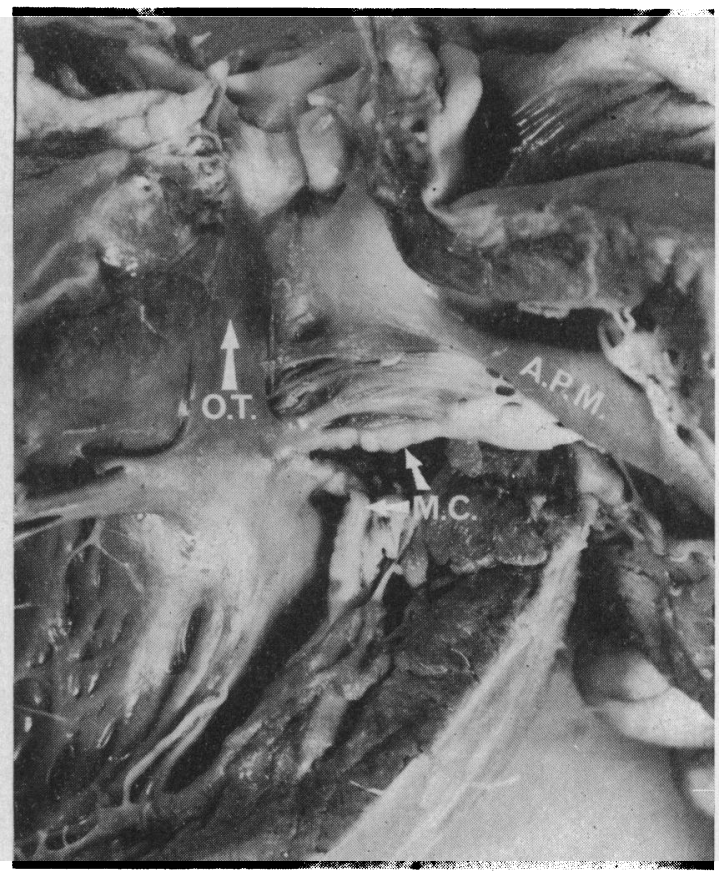

(b)

FIG. 5-(a) Heart opened to show the left ventricle and left atrium. The mitral valve is grossly deformed with a wedge of deficient valve tissue beneath the primum defect (O.P.). The chordæ are attached into the side instead of into the apex of the anterior papillary muscle (A.P.M.). (b) The same heart opened to show the narrowed aortic outflow tract (O.T.) and the mitral valve cleft with rolled thickened edges (M.C.). The apex of anterior papillary muscle (A.P.M.) is attached into the mitral valve ring. (Type II defect.)

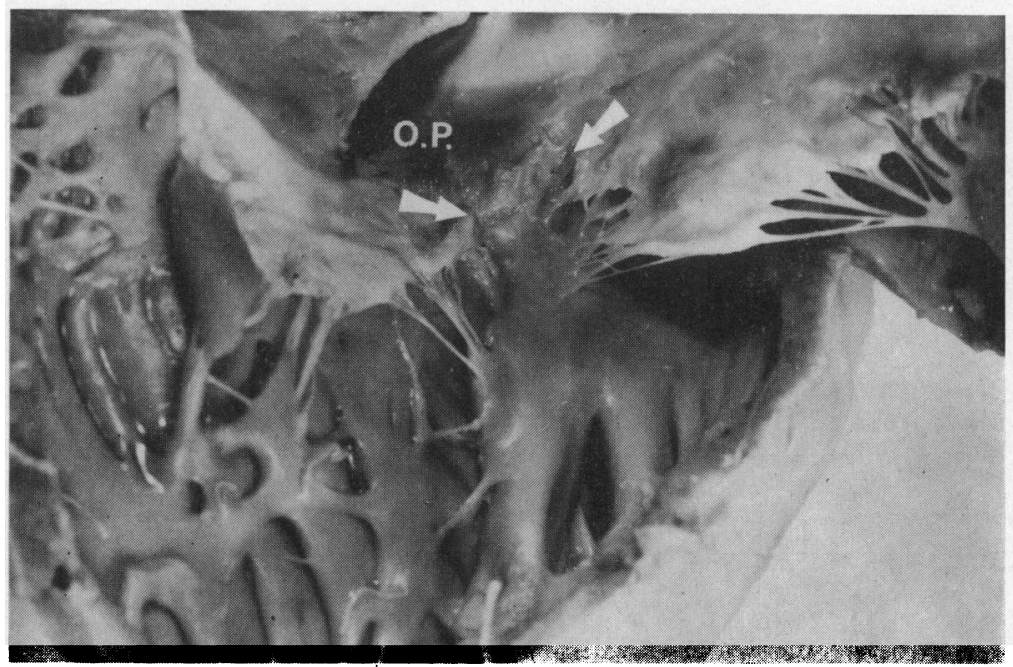

Fig. 6.-The same heart as in Fig. 5 opened to show the right ventricle, right atrium, and tricuspid valve. The arrows indicate the deficiency in the tricuspid valve tissue. O.P. $=$ Ostium primum. 
the septum) may render the cusp more mobile, but may also interfere with its stability and make it impossible to overcome the incompetence. Add the fact that the cleft is more often a wedgeshaped deficiency of tissue (Fig. 5), and the surgical difficulties can be appreciated. Success in correcting these cases depends upon the final integrity of the valve, and extreme precision is required to reconstitute the anterior cusp of such a malformed valve so that it has the necessary mobility, and is not made stenotic or left frankly incompetent especially as the extent of the abnormality and the actual amount of deficient tissue are not always easily appreciated.

The "cleft" in the tricuspid valve is rarely impressive. It is usually represented by a gap in the valve ring at the junction of the inferior and superior cushion contributions, with slight rolling of the cusp margins (Fig. 6). It probably has little functional importance. However, when such a gap is present it is often a pointer to the fact that there is an appreciable deficiency of tissue on the other side of the septum in the mitral anterior cusp.

The interatrial communication perhaps achieves greater importance than is its due. In most instances the septum primum has reached the optimal level for fusion to occur, but cannot do so because the tissues below it are underdeveloped and the septal defect is essentially between and below the valves. Similarly, the ventricular septum is always deficient to some extent and has a characteristic scooped-out appearance whether or not there is a defect in the accepted sense. The outflow tract of the left ventricle is usually elongated and narrowed because of the downward displacement of the mitral valve to attach itself to this scooped-out ventricular septum.

The course of the conducting tissue has been described by Lev (1958), and recently by Roos and Durrer (1964). The atrio-ventricular node is displaced posteriorly so that it lies under the coronary sinus, and the bundle skirts the lower edge of the defect until it reaches the crista, accompanies the septal band, and proceeds along the moderator band. In the complete form of the anomaly its course may be even more elongated, the bundle may dip more over the left side of the ventricular septum, and abnormalities of the left bundle-branch are more common. The elongated course of the main bundle-branch before it divides makes it very vulnerable to damage, and temporary or permanent heart block is always a possible hazard of operation.

Associated cardiovascular anomalies encountered in our patients were pulmonary valve stenosis in 2 cases, a secundum type atrial septal defect in 4 (including a large secundum defect in one case of transitional type who had no primum atrial defect), a left superior vena cava in 4 , and a hepatic vein draining into the coronary sinus in 2 . The foramen ovale was valvular in 4 cases. In one there was a separate muscular ventricular septal defect.

\section{Clinical Assessment}

Of the 29 patients, 15 were female and 14 were male, ranging in age from 2 months to 38 years. The age and sex distribution is shown in Table $I$.

The commonest symptoms in the group as a whole were a general lack of physical stamina, and repeated attacks of bronchitis. Considerable cardiac enlargement was present in all, but 6 patients were entirely symptom free; 4 of these had ostium primum defects (grade I), and the other 2 had

TABLE I

Age and Sex Distribution of Patients with Endocardial Cushion Defects

\begin{tabular}{c|c|c|c|c|c}
\hline $\begin{array}{c}\text { Grade of } \\
\text { defect }\end{array}$ & $\begin{array}{c}\text { No. of } \\
\text { patients }\end{array}$ & Adults & Children & Female & Male \\
\hline I & 16 & 4 & 12 & 7 & 9 \\
II & 10 & 1 & 9 & 6 & 4 \\
III & 3 & - & 3 & 2 & 1 \\
\hline Total & 29 & 5 & 24 & 15 & 14 \\
\hline
\end{tabular}


defects of transitional type (grade II). Heart failure was or had been present in 2 patients in grade I, and 3 patients in grade II; all had severe mitral incompetence, and 2 had pulmonary hypertension of moderate severity. The 3 children in grade III had been in heart failure most of their lives.

An associated extracardiac congenital deformity was a common finding. Of those with a bulging sternum 6 had pulmonary hypertension, 2 had severe mitral incompetence without pulmonary hypertension, and one had an uncomplicated ostium primum defect. In grade I, 2 were mentally retarded: one of these had a bifid uvula and deformed teeth; the other, a microcephalic, had associated severe pulmonary valve stenosis. One patient in grade II had hypospadias and a deformed chest together with pulmonary stenosis. Nine patients had a bulging sternum, 2 others had chest deformities, 5 had a high arched palate, and one had long fingers and kyphosis. Poor physical development was a notable feature in children with severe mitral incompetence or pulmonary hypertension.

Except for a single patient with an isolated ventricular septal defect of cushion type together with a cleft and incompetent mitral valve, the hæmodynamics and clinical findings in grades I and II were indistinguishable. These two grades will therefore be described together.

Two patients were cyanosed at rest; one had severe pulmonary valve stenosis associated with a grade I defect and in the other a left-sided vena caval system drained directly into the left atrium. Three patients with grade I defects and large left-to-right shunts became cyanosed on effort, despite a normal pulmonary resistance. The usual features of atrial septal defect rendered clinical assessment of associated mitral incompetence difficult and inaccurate. It was frequently difficult on purely clinical grounds to say whether or not the left ventricle contributed to the apex pulsation, and systolic murmurs at the apex and in the axilla were almost invariably present whether or not the mitral valve was incompetent. Indeed all four valves may contribute to the apical murmurs in cases of ostium primum atrial defect. In addition, encroachment of the elongated anterior cusp of the mitral valve upon the left ventricular outflow tract may give rise to aortic ejection murmurs. These may also be heard in any condition in which the mitral cusp is displaced, such as mitral incompetence caused by ruptured chordæ, and hypertrophic obstructive cardiomyopathy in which the mitral valve is distorted by the extreme muscular hypertrophy.

\section{INVESTIGATIONS}

Radiography. Marked cardiac enlargement and pulmonary plethora were seen in all patients without associated pulmonary stenosis. The presence of mitral incompetence could not be determined from the plain radiographs.

Electrocardiography. The characteristic features of endocardial cushion defects (ToscanoBarbosa, Brandenburg, and Burchell, 1956; Beregovich et al., 1960; Burchell, DuShane, and Brandenburg, 1960), namely left axis deviation (frontal plane axis between 0 and $-90^{\circ}$ ) with partial right bundle-branch block and a deep or slurred S wave in "posterior" leads II, III, and VF, were present in most cases. A long P-R interval (more than 0.2 sec. in adults) was present in 13 patients in grade I, 6 in grade II, and in all in grade III. Evidence of left atrial hypertrophy suggesting mitral incompetence was seen in only 6 patients in the whole series, and its presence or absence was no guide to the competence of the mitral valve.

In addition to the left axis deviation in the standard leads, which is the rule, 6 out of 7 patients with severe mitral incompetence showed evidence of left ventricular enlargement in the left-sided præcordial leads, the one exception being a 2 -year-old boy with very severe pulmonary hypertension. In atrial defects uncomplicated by mitral incompetence, the left ventricle is small and enveloped by the voluminous right heart chambers. The finding of a high voltage $\mathrm{qRS}$ complex in leads V5 to 7 instead of the expected RS was, therefore, a useful guide to the presence of left ventricular enlargement (Fig. 7a, b, and c). The classical electrocardiographic findings were modified by pulmonary hypertension or severe pulmonary stenosis. Three patients with severe pulmonary vascular disease, and one with severe pulmonary stenosis showed right axis deviation 


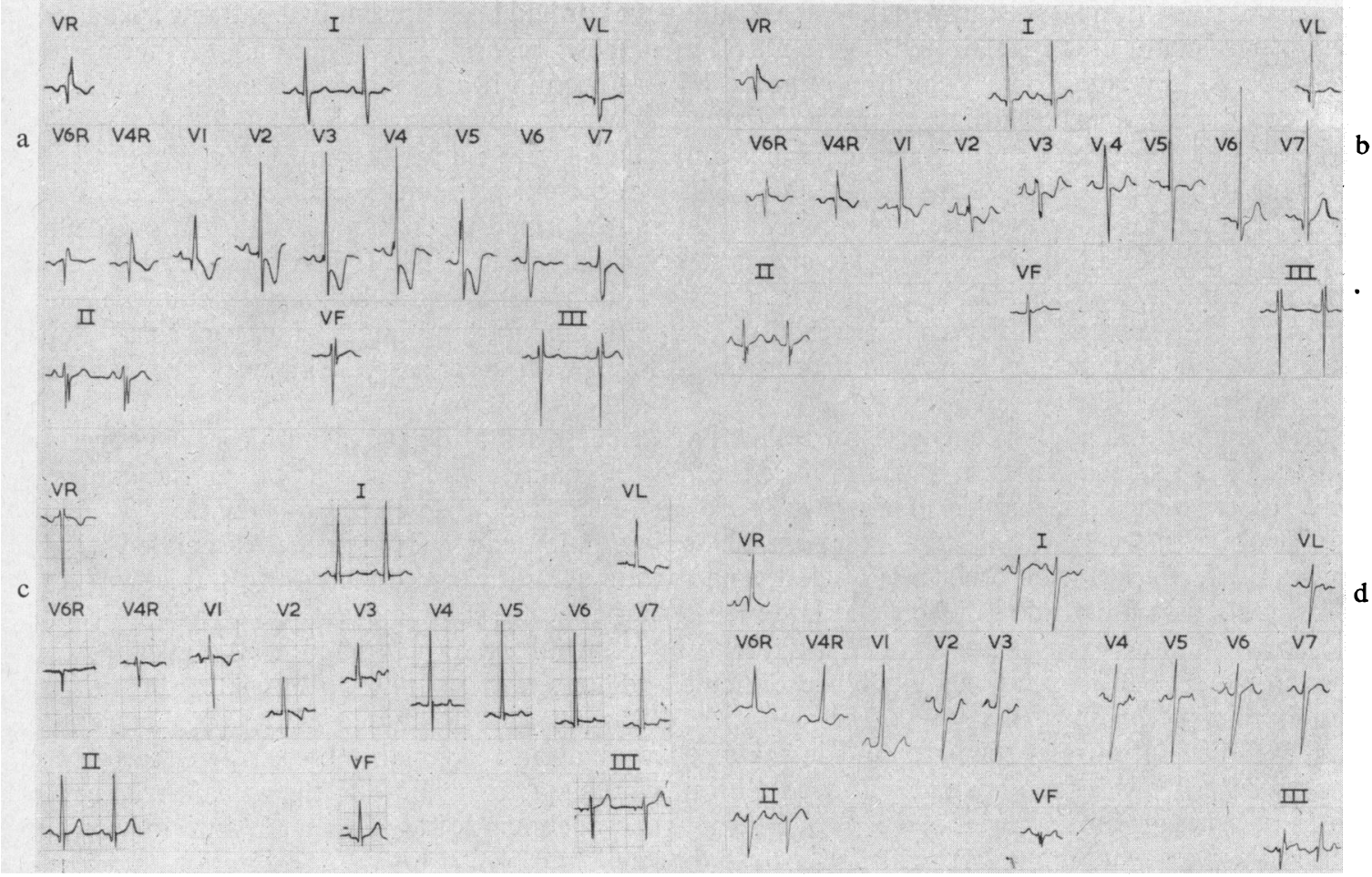

FIG. 7-(a) Typical electrocardiogram in a patient with an uncomplicated ostium primum (grade I defect) (mean qRS axis $-60^{\circ}$ in the frontal plane). This 7-year-old boy had a cleft mitral valve but no mitral incompetence. The right ventricle occupies the left præcordium, leads V5 to V7, shows an rS, and there is no evidence of left ventricular enlargement. (b) Typical electrocardiogram in a patient with an ostium primum defect and important mitral incompetence. The left ventricle occupies the left præcordium and leads V5 to V7 show a high voltage qRS reflecting a large left ventricle (mean qRS axis $-70^{\circ}$ ). (c) Electrocardiogram from a patient with an isolated cushion type ventricular septal defect and cleft, incompetent mitral valve. The mean qRS frontal axis $\left(+10^{\circ}\right)$ is unusually far towards the left for a child of 3 years and there is evidence of left ventricular hypertrophy (V1, V5 to V7). (d) Electrocardiogram from a 2-yearold boy with a complete atrio-ventricular canal (grade III defect), and severe pulmonary vascular disease. The mean qRS frontal axis is far to the right $\left(+200^{\circ}\right)$ or left $\left(-160^{\circ}\right)$, and there is no evidence of left ventricular enlargement. The deep S in II, III, and F are preserved and give the clue to the presence of an atrio-ventricular canal.

though the deep slurred S wave in standard lead II persisted and was the clue to the diagnosis of an endocardial cushion defect (Fig. 7d).

Cardiac Catheterization. Right heart catheterization was carried out in all but two patients. A left-to-right shunt at atrial level was shown with the pulmonary flow at least twice the systemic flow in all except one patient who had associated pulmonary stenosis and was deeply cyanosed. An additional left-to-right shunt at ventricular level was observed in two patients each in grade II and III. A left-to-right shunt solely at ventricular level was found in one patient who had a transitional type of defect with no atrial element to the septal defect (Neufeld et al., 1961). Since the pulmonary vascular resistance is usually below normal in uncomplicated atrial septal defect, significant pulmonary vascular disease was considered to be present when the pulmonary vascular resistance measured over two units, but this was not seen except in patients with either a large ventricular element to the septal defect or severe mitral incompetence. Thus, in patients with ostium primum defects, the presence of a raised pulmonary vascular resistance was taken as evidence of mitral regurgitation. 


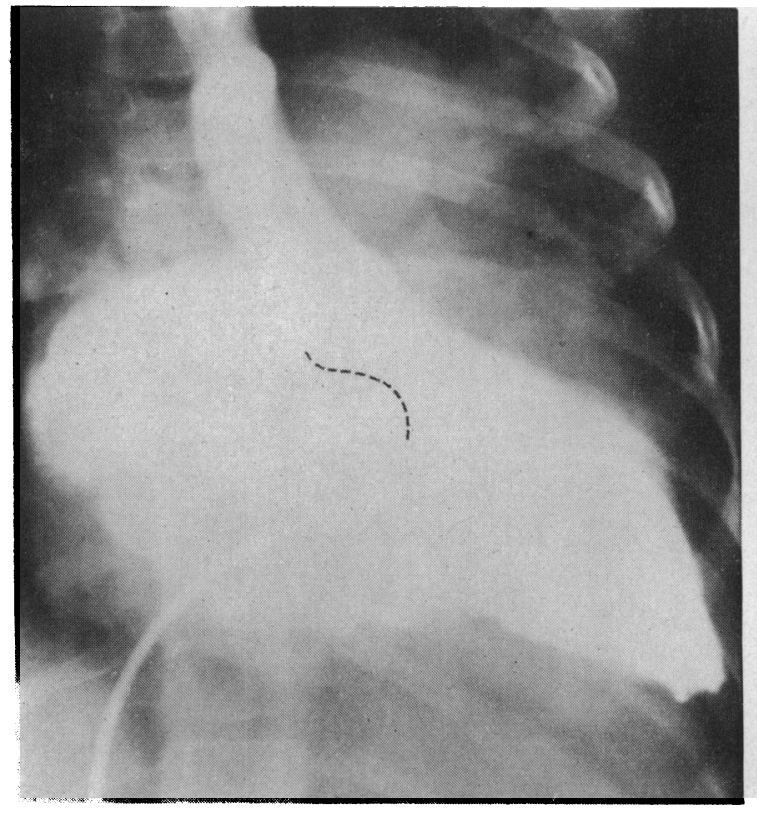

(a)

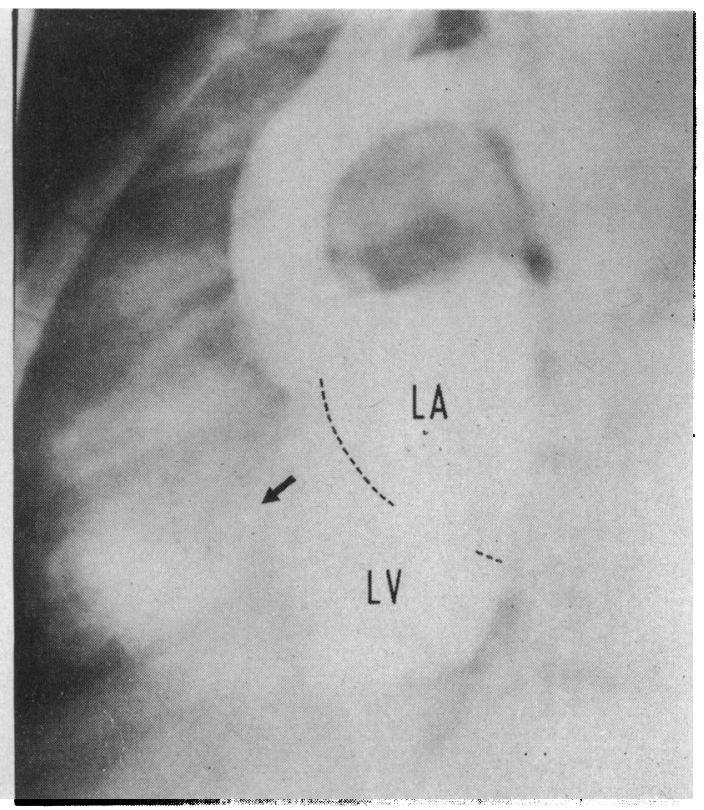

(b)

FIG. 8-Frontal view (a) of left ventricular (LV) angiogram (via the $\mathrm{A} / \mathrm{V}$ canal), showing severe mitral incompetence. In the lateral view (b) contrast is also seen beginning to fill the right atrium (arrow). The line of separation between LV and LA, which was plainly visible on the originals, has been retouched. $(\mathrm{LA}=$ left atrium. $\mathrm{LV}=$ left ventricle.)

The height and form of the atrial pressure pulse wave did not differ significantly in those with and those without mitral incompetence, probably because the regurgitant "V" wave was dissipated in the combined volumes of the two atria.

Angiocardiography. Right ventricular angiography was usually unhelpful in completing the anatomical diagnosis. Left ventricular contrast studies, however, are very useful, as Braunwald, Morrow, and Cooper (1959) and Baron et al. (1963) have emphasized, though we found that left ventricular angiography via the atrial defect was unreliable owing to artefactual mitral incompetence sometimes being caused by the passage of the catheter through the valve. Our more recent experience indicates that retrograde left ventricular angiography provides the following information: first, it reveals the presence, and reliably assesses the degree, of mitral incompetence (Fig. 8 and 9); second, it can show the presence of a tricuspid cleft and the presence and magnitude of a ventricular component of the septal defect (Fig. 9b); third, the characteristic shape of the left ventricular cavity may help to confirm the diagnosis (Fig. 10) since downward displacement of the mitral valve attachment renders the aortic outflow long and narrow by encroachment upon it of the elongated anterior mitral cusp-this appearance has been likened to a "goose neck" by the Mayo Clinic group (P. A. Ongley, personal communication, 1963). The angiocardiographic appearances in endocardial cushion defects have recently been lucidly described by Baron and his colleagues (1964), who suggested that the cleft in the mitral valve may actually be visible.

\section{Surgical Treatment}

Surgical correction using extracorporeal circulation was attempted in all our patients. The mitral cleft was repaired by direct suture when the deficiency was small, but insertion of a teflon felt patch covered with pericardium was the method of choice in the majority. Other associated defects were treated in the manner appropriate to them.

Five of the 16 patients of grade I $(31 \%), 6$ of 10 of grade II $(60 \%)$, and all 3 of grade III died. 


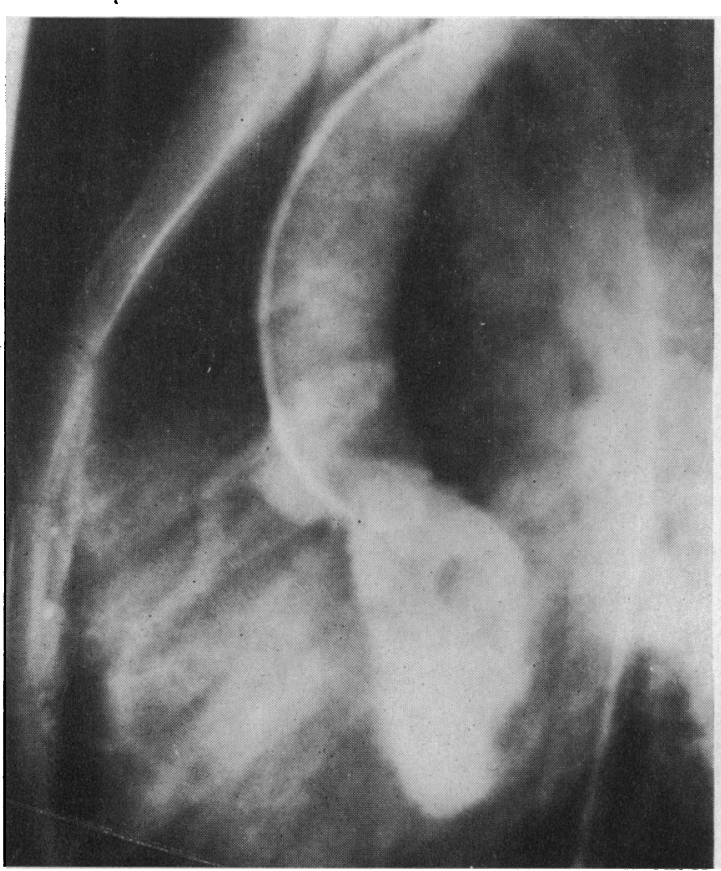

(a)

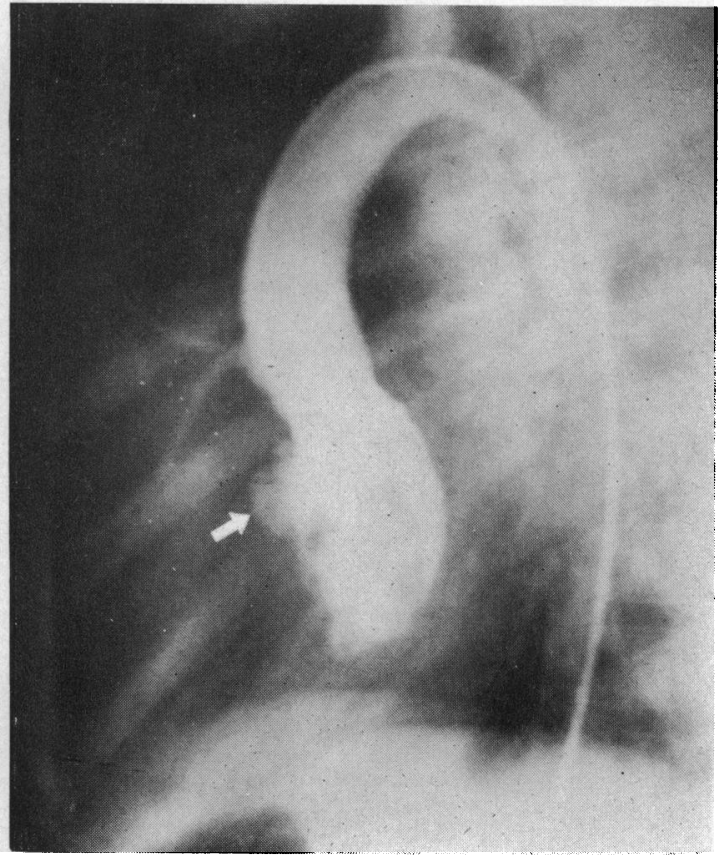

(b)

FIG. 9.-Retrograde LV angiograms, systolic phase, lateral projections, in patients with ostium primum endocardial cushion defects but no incompetence. (a) Grade I defect with no tricuspid cleft. (b) Transitional defect (grade IIa) with mitral and tricuspid clefts. Instead of the normal smooth appearance seen in (a), the anterior wall of the left ventricle shows an irregular pouch caused by contrast medium entering the $\mathrm{A} / \mathrm{V}$ canal in the region of the cleft tricuspid valve. It does not escape into the right heart chambers.

Table II shows the distribution of mortality and the causes of death. Between July 1957 and December 1959, 7 patients were operated upon and 5 died, 3 with heart block and 2 from complications arising from prolonged perfusion.

Since January 1960, 22 patients have been operated upon with 8 deaths. The 4 deaths occurring in the 18 patients with grade I and II defects were in each case a direct consequence of unrelieved mitral incompetence. There were no deaths attributable to heart block.

Apart from the technical difficulties inherent in dealing with complete canals (grade III defects), the two factors of greatest importance are the avoidance of complete heart block and precise

TABLE II

OPERATIVE Results

\begin{tabular}{|c|c|c|c|}
\hline Grade & No. of patients & No. of deaths & Remarks \\
\hline 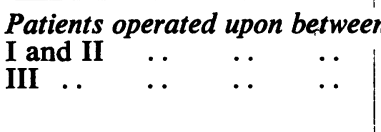 & $\begin{array}{c}\text { July } 1957 \text { and } D \\
6 \\
1\end{array}$ & cember 1959 & $\begin{array}{l}\text { Cardiac arrest after long perfusion; heart block } \\
\text { Unrelieved pulmonary hypertension and heart } \\
\text { block }\end{array}$ \\
\hline 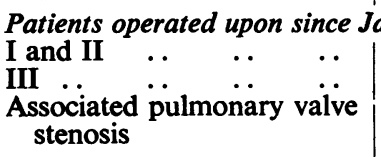 & $\begin{array}{c}1960 \\
18 \\
2 \\
2\end{array}$ & $\begin{array}{l}4 \\
2 \\
2\end{array}$ & $\begin{array}{l}\text { Unrelieved mitral incompetence } \\
1 \text { pulmonary œedema; } 1 \text { hypoplastic left ventricle } \\
1 \text { pulmonary œedema; } 1 \text { post-operative hæmorrhage }\end{array}$ \\
\hline
\end{tabular}




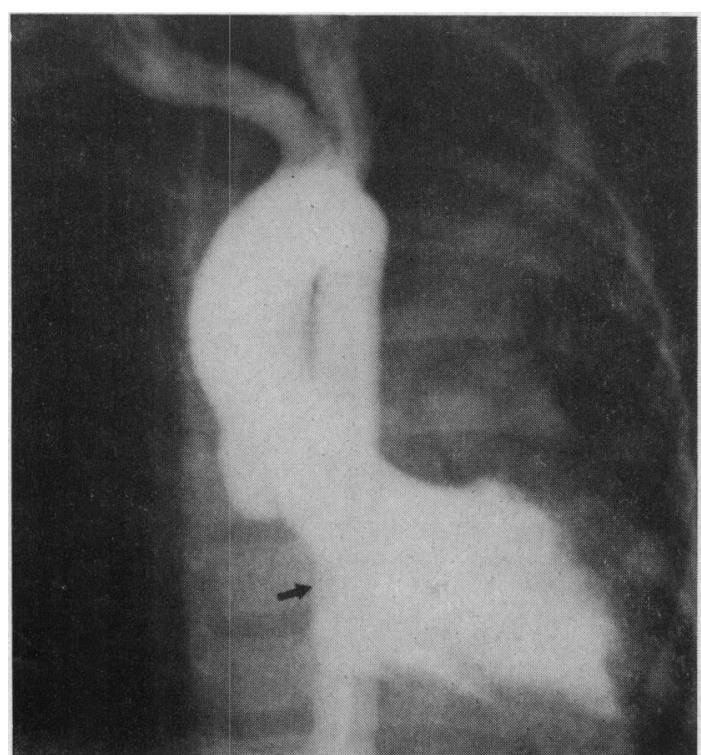

(a)

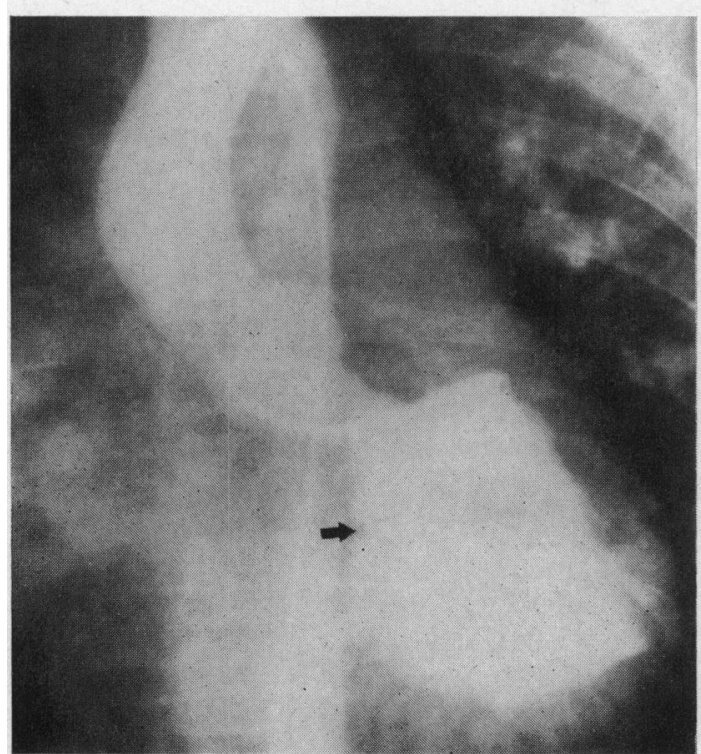

(c)

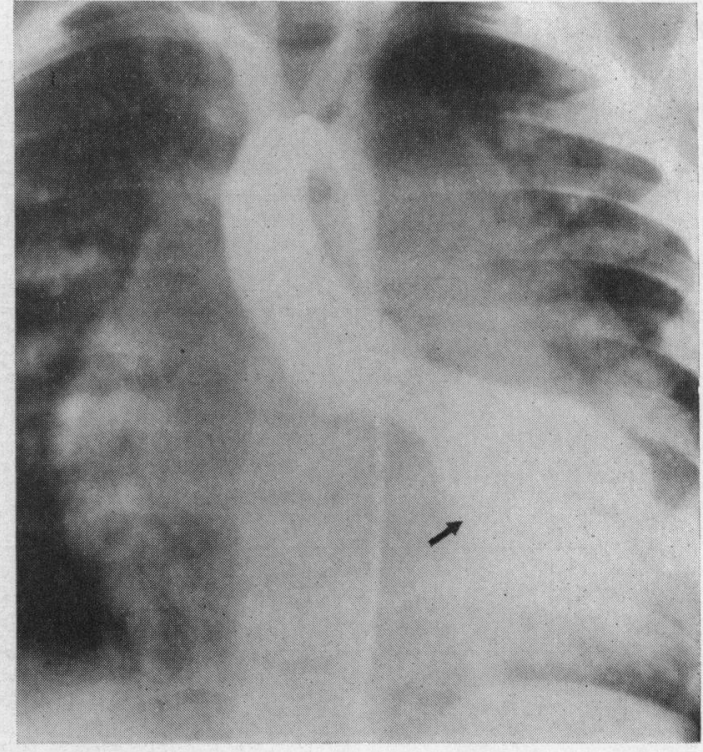

(b)

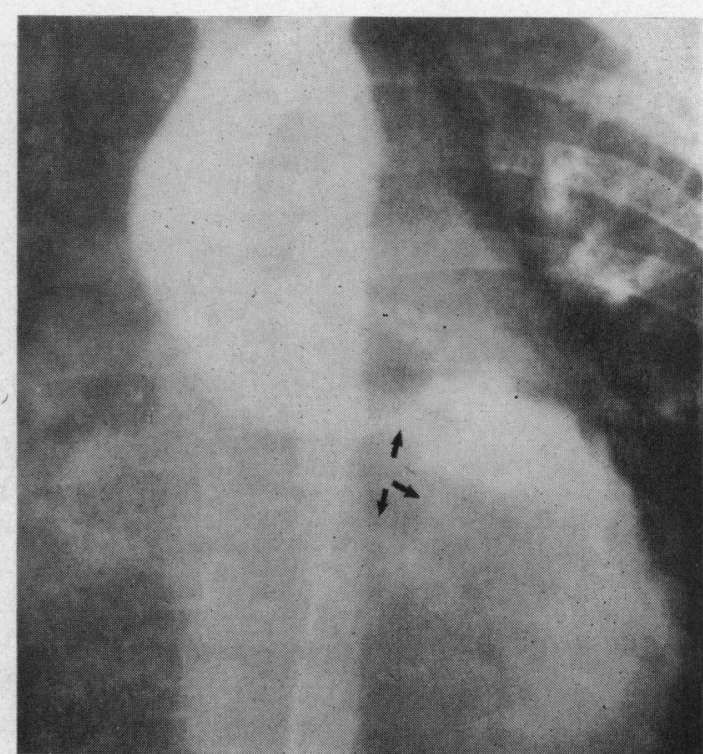

(d)

FIG. 10.-Retrograde LV angiograms. Systolic phase. Frontal projections. (a) Normal appearance; the LV outflow tract is broad. (b) A patient with an ostium primum (transitional type) showing the "goose neck" deformity of the outflow tract. The arrow points to the site of attachment of the chordæ of the posterior cusp. (c) and (d) A similar "goose neck" in a patient with a grade I ostium primum defect but no mitral valve cleft. Though the anterior cusp of the mitral valve was not cleft in this patient, its displacement, elongation, and abnormal plane of insertion was otherwise typical of these defects. (c) Systole. The arrow marks the point of insertion of the normal posterior mitral cusp. (d) Diastole. The long anterior cusp of the mitral valve (arrowed) shows as a crescentic filling defect in the outflow tract. 
TABLE III

InCidence of Complete Heart Block due to Operation

\begin{tabular}{l|c|c|c|c}
\hline \multirow{2}{*}{ Grade } & \multirow{2}{*}{ No. of patients } & \multicolumn{3}{|c}{ Heart block } \\
\cline { 2 - 4 } & & Temporary & Permanent & Died \\
\hline I & 16 & 2 & 1 & 1 \\
II & 10 & 1 & 2 & 2 \\
III & 3 & - & 1 & 1 \\
\hline Total & 29 & 3 & 4 & 4 \\
\hline
\end{tabular}

TABLE IV

Results OF OPERATION RELATED TO Mitral INCOMPETENCE

\begin{tabular}{|c|c|c|c|c|c|c|c|}
\hline Grade & No. of patients & \multicolumn{2}{|c|}{$\begin{array}{l}\text { Pre-operative } \\
\text { mitral incompetence }\end{array}$} & \multicolumn{2}{|c|}{$\begin{array}{l}\text { Post-operative } \\
\text { mitral incompetence }\end{array}$} & \multicolumn{2}{|c|}{ Clinical result } \\
\hline I & 11 & $\begin{array}{l}\text { Severe } \\
\text { Moderate } \\
\text { Slight } \\
\text { None }\end{array}$ & $\begin{array}{l}1 \\
4 \\
4 \\
2\end{array}$ & $\begin{array}{l}\text { Moderate } \\
\text { Slight } \\
\text { None }\end{array}$ & $\begin{array}{l}\overline{6} \\
3 \\
2\end{array}$ & Symptom free & 11 \\
\hline II & 4 & $\begin{array}{l}\text { Moderate } \\
\text { None }\end{array}$ & $\begin{array}{l}2 \\
1\end{array}$ & $\begin{array}{l}\text { Moderate } \\
\text { None }\end{array}$ & $\begin{array}{l}3 \\
1\end{array}$ & Symptom free & 4 \\
\hline
\end{tabular}

correction of the mitral valve deformity. The incidence of complete heart block is shown in Table III, but none of the last 24 patients operated upon since January 1960 died from this cause.

The post-operative course of survivors was stormy unless the mitral incompetence had been relieved, but even in those patients in whom some degree of mitral incompetence still remains, the ultimate clinical result has been rewarding (Table IV).

\section{UNCORRECTABLE Mitral INCOMPETENCE}

Of particular interest were the four patients whose mitral valve deformity was found to be irreparable by ordinary surgical means. All four had been regarded clinically as representative of the least complex form of endocardial cushion defect, i.e. that of ostium primum with a cleft mitral valve. They did have severe mitral incompetence, but before operation did not differ from the other patients in the series who also had severe mitral incompetence but whose valves offered no particular obstacle to successful correction. One patient (G.D.) had severe mitral incompetence with only a small atrial defect, a combination that forms a recognizable clinical syndrome (Brockenbrough et al., 1962).

The individual case histories of these four patients are given below.

M.G. The main disability of this 10-year-old girl was repeated chest infection which she had suffered since the age of 2 years. Her other symptoms were trivial and she was an active child. Increasing chest deformity had been noticed in the past few years.

On examination in February 1960 she was exceedingly thin and had a gross sternal bulge. Cyanosis was absent. She showed florid signs of atrial septal defect, but no cardiac failure. The arterial pulses were of small volume, the venous pressure $5 \mathrm{~cm}$. with equal "a" and " $\mathrm{v}$ " waves, and the cardiac impulses were turbulent. Besides a pulmonary ejection systolic murmur and an obvious tricuspid diastolic murmur, a loud pansystolic murmur could be heard at the tricuspid area, at the apex, and in the axilla. The electrocardiogram was typical of an atrio-ventricular canal and evidence of left ventricular enlargement was revealed 
in the præcordial leads (Fig. 11). Chest radiography showed a cardiothoracic ratio of 73 per cent and gross overfilling of the lungs. Right heart catheterization had been performed elsewhere in 1959 and had revealed an atrial septal defect with a pulmonary flow of four times the systemic flow. All four chambers of the heart had been entered, the left and right atrial pressures were equal, and the pulmonary vascular resistance was under one unit.

Comment. This child's mitral incompetence was not really occult, though its severity was underestimated. The significance of the electrocardiogram was not appreciated and angiocardiography was not undertaken. She demonstrated well how large compliant atria absorb the mitral regurgitant " $v$ " wave, and her atrial pressure did not give any clue to the disastrous degree of uncorrectable mitral regurgitation which was found. No less than three operations were undertaken in a vain effort to improve mitral valve function. Valve replacement would have been the only means of helping her, but was not at that time available.

G.D. This 2-year-old boy with an ostium primum atrial septal defect was strikingly breathless and had been in heart failure for the six months before operation in September 1961. Pulmonary hypertension and mitral incompetence were dominant clinically, but the presence of an associated atrial septal defect was suggested by a tricuspid flow murmur and fixed splitting of the second sound. The electrocardiogram showed right axis deviation and no evidence of left ventricular enlargement, but a long P-R interval, bi-atrial enlargement, and a deep $\mathrm{S}$ in lead II suggested an atrio-ventricular canal (Fig. 11). Cardiac catheterization confirmed that he had a left-to-right interatrial shunt with pulmonary flow twice the systemic flow; the left atrial pressure was $20 \mathrm{~mm}$. $\mathrm{Hg}$ compared with a right atrial pressure of $8 \mathrm{~mm} . \mathrm{Hg}$, and he had severe pulmonary hypertension.

Comment. This child's severe dyspnœa was a pointer to the fact that the high left atrial pressure was not being dissipated by transmission to the right atrium, and the disparity between the measured left and right atrial pressures again indicated that the atrial defect was small. At operation the mitral valve was severely disorganized and surgical closure of the atrial defect only made matters worse, for the function of the mitral valve could not be improved, and the full force of the mitral regurgitation was now directed into the pulmonary veins. Two attempts to correct the mitral incompetence were made, but he died after the second operation with the mitral incompetence still unrelieved.

M.D.M. This 10-year-old girl's situation was almost identical to that experienced previously in patient M.G. She was an active child whose main symptoms were failure to gain weight and a certain lack of stamina. The venous pressure in the neck was normal, but the electrocardiogram showed evidence of left 
ventricular enlargement as well as the usual features of atrio-ventricular canal (Fig. 11). Chest radiographs showed a considerably enlarged heart. At right heart catheterization all four heart chambers were entered, the left-to-right shunt was purely interatrial with pulmonary flow twice the systemic and a pulmonary vascular resistance of two units. It was appreciated that she had severe mitral regurgitation associated with an ostium primum defect and so confirmatory left ventricular angiography was considered necessary. It was also realized that the surgical risks would be great, but in view of the very large heart, and the low pulmonary vascular resistance, surgical correction was advised. At operation in January 1963, the atrial communication was successfully patched, but much of the mitral valve incompetence was due not to the cleft but to abnormal tethering of the anterior mitral cusp to the ventricular septum by shortened chordæ, and the valve could not be made competent. She died after several months in congestive heart failure.

Comment. Closure of the atrial defect led to pulmonary œdema in the presence of uncorrected mitral regurgitation.

B.T. This 14-year-old girl was completely symptom free. She had signs of an atrial septal defect which electrocardiography showed to be of the primum type. Her heart was considerably enlarged radiologically. Hæmodynamic studies confirmed that she had an interatrial shunt with a pulmonary flow twice the systemic flow and a normal pulmonary artery pressure.

Comment. Though she had an apical systolic murmur of moderate intensity, a heart that seemed rather too large for the estimated size of the shunt, and electrocardiographic evidence of left ventricular hypertrophy (Fig. 11), mitral incompetence was erroneously assessed as slight and left ventricular angiography was not done.

This was the most disappointing case. The mitral valve could not be rendered competent and she developed intractable pulmonary œdema.

In all these patients the sequence of events at operation was remarkably constant. The defect was approached through a right atriotomy in the usual way, and from this aspect the anatomy of the valve had the expected appearance. The edges of the cleft were sutured or patched, selected short chordæ were severed, but the severity of the incompetence was not reduced. The primum defect was then closed, a patch being used if necessary. The left atrial pressure then became drastically raised, and remained so despite all measures. Indeed, in B.T., the anatomy was restored as nearly as possible to its original state, but the left atrial pressure remained raised, and the patient succumbed from severe acute pulmonary œdema. One patient (M.G.) survived for a few days, and was operated upon again with the same result. One (M.D.M.) survived for several months, but with severe cardiac failure.

Necropsy was performed only in two cases (G.D. and B.T.) and showed the mitral valve deformity to be of the kind described in the section on anatomy, with a marked deficiency of cusp tissue, with the margins of the cleft tethered by short thick chordæ to the side of a papillary muscle, the apex of which was inserted into the mitral valve ring (Fig. 5a). The tragically similar course of the other two patients suggests that they had the same anatomical deformity.

\section{DisCUSSION}

The high mortality attending the surgical correction of endocardial cushion defects (Cooley et al., 1958; Kiely et al., 1958; McGoon, DuShane, and Kirklin, 1959; Cooley, 1960; Dubost and Blondeau, 1960; Ellis, McGoon, and Kirklin, 1960; Gerbode et al., 1961; Maloney, Marable, and Mulder, 1962) prompted this review of our total experience to try to establish which factors were responsible for the large number of deaths. Though the diagnosis of "endocardial cushion defect" usually presents little difficulty, the details of the anatomy within this general designation are less readily determined.

Pre-operative clinical assessment of the degree of mitral incompetence has proved unreliable. The auscultatory findings are often misleading because the large size of the right ventricle permits tricuspid and pulmonary systolic murmers to be heard at the apex and axilla where they may be 
mistaken for the murmur of mitral incompetence. Some guidance may be obtained from the electrocardiogram. Although all patients (except two with gross pulmonary hypertension and one with associated pulmonary stenosis) showed left axis deviation, evidence of left ventricular enlargement was only seen in the presence of mitral regurgitation. It was recognized by the presence of a high voltage $\mathrm{qR}$ complex in the left præcordial leads, which was not seen in uncomplicated ostium primum defects. In our series, pulmonary vascular disease was found only in those patients who had either significant mitral incompetence or a ventricular component to the septal defect, and these features are best demonstrated by retrograde left ventricular angiography.

Though the degree of mitral incompetence can be assessed angiographically, and the elongated cleft anterior mitral cusp recognized, it is not yet possible to distinguish between those cases in which mitral incompetence can be corrected by surgery, and those of the type that we have described in which it seems that nothing short of a valve replacement is likely to be effective. The dangers of incomplete repair of the incompetent mitral valve combined with complete repair of the atrial communication have been emphasized also by Gerbode et al. (1961) and by Scott et al. (1962b).

Patients with a complete atrio-ventricular canal and a single atrio-ventricular valve do not seem to have as much incompetence as those in whom the valve rings have partially formed. Perhaps this is because the single valve has adequate cusp tissue, which, though not joined in the midline, has more normal chordal and papillary muscle attachments and more mobility through not being tethered to the top of the ventricular septum. It is unfortunate that the severer type of mitral valve deformity can occur without any distinguishing clinical manifestation in just the form of the anomaly that is generally regarded as the most suitable for correction. It is interesting that mitral incompetence seems to be important mainly in patients with the less complicated forms of the anomaly.

\section{SUMMARY}

The pathological anatomy of the various types of common atrio-ventricular canal has been reviewed in the light of 29 patients who were operated upon for open repair of the defects.

There were 16 patients with persistent ostium primum with cleft mitral valve (grade I), 10 with transitional form (grade II), and 3 with complete atrio-ventricular canal (grade III). Two had associated pulmonary valve stenosis, 4 an associated secundum type of atrial septal defect, 4 a left superior vena cava, and 2 a hepatic vein draining into the coronary sinus. One patient had a separate muscular ventricular septal defect. Fourteen patients died after operation, a mortality of 48 per cent. All 3 patients with complete atrio-ventricular canal died after the operation, but 5 patients with ostium primum defects also died. Of these deaths, in patients who appeared clinically to have uncomplicated ostium primum defects, 4 were a direct result of persisting mitral regurgitation, and it was this unexpectedly high mortality in the seemingly good risk patients that prompted the present study. The presence of mitral incompetence also determined the occurrence of pulmonary hypertension and pulmonary vascular disease in patients with ostium primum defects and further added to the operative risk in this group. It is felt that the only reliable method of pre-operative assessment of mitral valve function is by retrograde left ventricular angiography, though some help can be obtained from the electrocardiogram, where signs of left ventricular hypertrophy indicate severe mitral incompetence.

Ostium primum defects with cleft but competent mitral valves can be operated upon with almost as low an operative morbidity and mortality as ostium secundum defects, but when mitral regurgitation is more than slight, a high operative risk must be faced. It is possible that the hopelessly deformed mitral valves will soon be recognizable angiographically, but, at the present time, it is the authors' view that operations should only be carried out in such patients when the urgency is great and where a mitral prosthesis is available.

The outcome of surgery in partial atrio-ventricular canal is largely determined by the preoperative competence of the mitral valve, as surgical repair of the cleft improves its function only in a limited number of cases. It is vital to detect those patients with serious pre-operative mitral regurgitation, for it is in these patients that the surgical mortality is high. 
We should like to thank Professor J. F. Goodwin and Professor R. E. Steiner for much constructive criticism; we also gratefully acknowledge the help of the Photographic Department who prepared the illustrations and Mrs. A. Cartwright and Miss B. Ferrar who were responsible for the secretarial work.

\section{REFERENCES}

Baron, M. G., Wolf, B. S., Steinfeld, L., and Gordon, A. J. (1963). Left ventricular angiocardiography in the study of ventricular septal defects. Radiology, 81, 223.

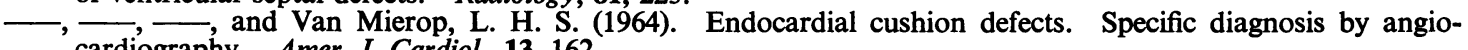
cardiography. Amer. J. Cardiol., 13, 162.

Beregovich, J., Bleifer, S., Donoso, E., and Grishman, A. (1960). The vectorcardiogram and electrocardiogram in persistent common atrioventricular canal. Circulation, 21, 63.

Braunwald, E., Morrow, A. G., and Cooper, T. (1959). Left ventricular angiocardiography in the diagnosis of persistent atrioventricular canal and related anomalies. Amer. J. Cardiol., 4, 802.

Brockenbrough, E. C., Braunwald, E., Roberts, W. C., and Morrow, A. G. (1962). Partial persistent atrioventricular canal simulating pure mitral regurgitation. Amer. Heart J., 63, 9.

Burchell, H. B., DuShane, J. W., and Brandenburg, R. O. (1960). The electrocardiogram of patients with atrioventricular cushion defects (defects of the atrioventricular canal). Amer. J. Cardiol., 6, 575.

Campbell, M., and Missen, G. A. K. (1957). Endocardial cushion defects. Common atrio-ventricular canal and ostium primum. Brit. Heart J., 19, 403.

Cooley, D. A. (1960). Results of surgical treatment of atrial septal defects; particular consideration of low defects including ostium primum and atrioventricular canal. Amer. J. Cardiol., 6, 605.

-, Latson, J. R., and Keats, A. S. (1958). Surgical considerations in repair of ventricular and atrial septal defects utilizing cardiopulmonary bypass. Experience with 104 cases. Surgery, 43, 214.

Dubost, C., and Blondeau, P. (1960). The surgical repair of persistent atrioventricular canal. Results in 26 operative cases. Amer. J. Cardiol., 6, 611.

Edwards, J. E. (1960). The problem of mitral insufficiency caused by accessory chordæ tendineæ in persistent common atrioventricular canal. Proc. Mayo Clin., 35, 299.

Ellis, F. H., McGoon, D. C., and Kirklin. J. W. (1960). Surgical management of persistent common atrioventricular canal. Amer. J. Cardiol., 6, 598.

Gerbode, F., Johnston, J. B., Robinson, S., Harkins, G. A., and Osborn, J. J. (1961). Endocardial cushion defects: diagnosis and technique of surgical repair. Surgery, 49, 69.

Kiely, B., Adams, P., Jr., Anderson, R. C., and Lester, R. G. (1958). The ostium primum syndrome. A.M.A. J. Dis. Child., 96, 381.

Lev, M. (1958). The architecture of the conduction system in congenital heart disease. I. Common atrioventricular orifice. A.M.A. Arch. Path., 65, 174.

McGoon, D. C., DuShane, J. W., and Kirklin, J. W. (1959). The surgical treatment of endocardial cushion defects. Surgery, 46, 185.

Maloney, J. V., Marable, S. A., and Mulder, D. G. (1962). The surgical treatment of common atrioventricular canal. J. thorac. cardiovasc. Surg., 43, 84.

Neufeld, H. N., Titus, J. L. DuShane, J. W., Burchell, H. B., and Edwards, J. E. (1961). Isolated ventricular septal defect of the persistent common atrio-ventricular canal type. Circulation, 23, 685.

Roos, J. P., and Durrer, D. (1964). Epicardial excitation in ventral atrial septal defect (ASD I). In Proceedings of the British Cardiac Society. Brit. Heart J., 26, 136.

Scott, L. P., Hauck, A. J., and Nadas, A. S. (1962a). Endocardial cushion defect with pulmonic stenosis. Circulation, 25, 653 .

,$- \frac{1}{2}$, and Gross, R. E. (1962b). Endocardial cushion defect. Preoperative and postoperative survey. Circulation, 26, 218.

Toscano-Barbosa, E., Brandenburg, R. O., and Burchell, H. B. (1956). Electrocardiographic studies of cases with intracardiac malformations of the atrioventricular canal. Proc. Mayo Clin., 31, 513.

Van Mierop, L. H. S., Alley, R. D., Kausel, H. W., and Stranahan, A. (1962). The anatomy and embryology of endocardial cushion defects. J. thorac. cardiovasc. Surg., 43, 71 . 